\title{
Prevalência sorológica e molecular de Babesia bovis e Babesia bigemina em búfalos (Bubalus bubalis) na Ilha de Marajó, Pará ${ }^{1}$
}

\author{
Jenevaldo B. Silva ${ }^{2 *}$, Cinthia T. A. Lopes ${ }^{3}$, Cleyton P. Pinheiro ${ }^{3}$, Danilo H.S. Lima ${ }^{3}$, \\ Roberto S. L. Silva ${ }^{3}$, Adivaldo H. Fonseca ${ }^{4}$, Flábio R. Araújo ${ }^{5}$ e José D. Barbosa-Neto ${ }^{3}$ \\ ABSTRACT.- Silva J.B., Lopes C.T.A., Pinheiro C.P., Lima D.H.S., Silva R.S.L., Fonseca A.H., Araújo \\ F.R. \& Barbosa-Neto J.D. 2013. [Molecular and serological prevalence of Babesia bovis \\ and Babesia bigemina in water buffaloes (Bubalus bubalis) on Marajo Island, State of \\ Pará, Brazil.] Prevalência sorológica e molecular de Babesia bovis e Babesia bigemina em \\ búfalos (Bubalus bubalis) na Ilha de Marajó, Pará. Pesquisa Veterinária Brasileira 33(7):847- \\ 850. Departamento de Epidemiologia e Saúde Pública, Universidade Federal Rural do Rio de \\ Janeiro, BR 465 Km 7, Seropédica, RJ 23890-000, Brazil. E-mail: jenevaldo@hotmail.com \\ The aim of the study was to estimate the prevalence of Babesia bovis and Babesia bige- \\ mina in water buffaloes of the Marajó Island, State of Pará, Brazil. We used an indirect en- \\ zyme-linked immunosorbent assay (iELISA), with total antigen containing proteins outer \\ surface, and polymerase chain reaction (qPCR), involving the use of SYBR Green based on \\ amplification of a small fragment of the cytochrome $b$ gene. The prevalence of positive ani- \\ mals in iELISA to B. bovis B. bigemina and mixed infection was $24.87 \%(199 / 800), 20.75 \%$ \\ $(166 / 800)$ and $18.75 \%(150 / 800)$, respectively. Using the PCR, the presence of B. bovis was \\ detected in 15\% (18/199) and B. bigemina in 16\% (19/199) of animals, and of these, 58\% \\ $(11 / 19)$ presented co-infected by the two agents. The results show a low prevalence of an- \\ tibodies anti-B. bovis and anti-B. bigemina in water buffaloes from Marajó Island. However, \\ it was observed that the agents of bovine babesiosis circulate in buffaloes, and these may \\ act as reservoirs.
}

INDEX TERMS: Babesia bovis, Babesia bigemina, buffaloes, Bubalus bubalis, ELISA, qPCR, Marajó Island.

RESUMO.- 0 objetivo do estudo foi testar a prevalência sorológica e molecular de Babesia bovis e Babesia bigemina em búfalos da Ilha de Marajó, Pará. Foi utilizado ensaio de imunoadsorção enzimático indireto (iELISA) com antígeno total contendo proteínas de superfície externa e reação em cadeia da polimerase (qPCR), envolvendo o uso de SYBR

\footnotetext{
${ }^{1}$ Recebido em 2 de outubro de 2012.

Aceito para publicação em 29 de abril de 2013.

${ }^{2}$ Laboratório de Imunodiagnóstico, Departamento de Patologia Veterinária, Facudade de Ciências Agrárias e Veterinárias (FCAV), Universidade Estadual Paulista (Unesp), Via de Acesso Prof. Paulo Donato Castellane s/n, Jaboticabal, SP 14884-900, Brasil. *Autor para correspondência: jenevaldo@hotmail.com

${ }^{3}$ Universidade Federal do Pará, Instituto de Medicina Veterinária, Via de Acesso BR 316, Km 62, Bairro Saudade (atrás do Instituto Federal do Pará (IFPA)), Castanhal, PA 68740-970, Brasil. E-mail: diomedes@ufpa.br

${ }^{4}$ Laboratório de Doenças Parasitárias, Departamento de Epidemiologia e Saúde Pública, Universidade Federal Rural de Rio de Janeiro (UFRRJ), BR 465 Km 7, Seropédica, RJ23890-000, Brasil. E-mail: adivaldo@ufrrj.br

${ }^{5}$ Embrapa Gado de Corte, Rodovia BR $262 \mathrm{Km} \mathrm{4,} \mathrm{Campo} \mathrm{Grande,}$ MS79002-970, Brasil. E-mail: flabio@cnpgc.embrapa.br.
}

Green com base na amplificação de um pequeno fragmento de gene do citocromo $b$. A prevalência de animais positivos no ELISA para B. bovis, B. bigemina e para infecção mista foi de $24.87 \%$ (199/800), 20.75\% (166/800) e $18.75 \%$ (150/800), respectivamente. Na PCR foi detectado a presença de B. bovis em $15 \%(18 / 199)$ e de B. bigemina em 16\% (19/199) dos animais, sendo que destes, 58\% $(11 / 19)$ apresentavam-se co-infectados pelos dois agentes. Os resultados mostram uma baixa prevalência de anticorpos anti- $B$. bovis e anti- $B$. bigemina em búfalos da Ilha do Marajó. Porém, observou-se que os agentes da babesiose bovina circulam em búfalos, podendo estes atuar como reservatórios.

TERMOS DE INDEXAÇÃO: Babesia bovis, Babesia bigemina, búfalos, Bubalus bubalis, ELISA, qPCR, Ilha de Marajó.

\section{INTRODUÇÃo}

O Brasil possui o maior rebanho de búfalos do ocidente e aproximadamente um terço do rebanho nacional encontra- 
-se na Ilha de Marajó, estado do Pará (IBGE 2008). Nas últimas decadas a bubalinocultura tem ganhado destaque no cenário nacional, deixando de ser apenas uma alternativa para a ocupação de terras impróprias para a criação de bovinos e passando a ser uma opção economicamente rentável. Com isso, a preocupação com manejo sanitário tem aumentado consideravelmente, pois aspectos clínicos, patológicos e epidemiológicos ainda são pouco estudados no país.

As babesioses bovina, causadas por Babesia bovis e $\mathrm{Ba}$ besia bigemina, são doenças de grande impacto econômico em todo o mundo. A infecção concomitante destes dois microrganismos, juntamente com a rickettsia Anaplasma marginale, é responsável pela enfermidade conhecida como Tristeza Parasitária Bovina (Grise et al. 2002). Espécies do gênero Babesia podem infectar diferentes hospedeiros, como ruminantes selvagens, canídeos, felídeos, roedores, inclusive o búfalo d'água e o búfalo africano, por meio de vetores biológicos e mecânicos (De la Fuente et al. 2005). Esta enfermidade é responsável por perdas significativas com mortalidade e redução da produção, além de gastos na utilização de medicamentos.

0 diagnóstico da babesiose tem sido feito por identificação dos parasitos em esfregaço sanguineo. Porém, embora rápido e barato, este teste não apresenta alta sensibidade, sendo indicado apenas para animais com doença clínica, por gerar resultados inconsistentes quando empregado em animais com infecção subclínica ou crônica (Terkawi et al. 2011). A partir da década de 1990, a Reação em Cadeia da Polimerase (PCR) tem apresentado maior sensibilidade e especificidade do que o diagnóstico por microscópia óptica (Fahrimal et al. 1992, Figueroa et al. 1993). Além dos testes moleculares, os testes sorológicos, ensaio de imunoadsorção enzimático (ELISA) e a reação de imunofluorescência indireta (RIFI), tem monstrado alta capacidade de detectar anticorpos em animais cronicamente infectados, sendo frequentemente utilizados em estudos de levantamentos epidemiológicos (Araújo et al. 1998).

Assim, a associação entre estudos moleculares e sorológicos tem mostrado ser uma poderosa ferramenta para levantamentos epidemiológicos, sobretudo em agentes que se apresentam em baixa prevalência (Goo et al. 2008, Terkawi et al. 2011). Neste contexto, o objetivo do estudo foi detectar por ELISA e PCR B. bovis e B. bigemina em búfalos na Ilha de Marajó, Estado do Pará, Brasil.

\section{MATERIAL E MÉTODOS}

O estudo foi realizado no município de Soure, microrregião do Arari, Ilha do Marajó, estado do Pará, Brasil. A Ilha localiza-se a uma latitude de $00^{\circ} 43^{\prime} 00^{\prime \prime}$ sul e a uma longitude de 4831'24" oeste, a uma altitude de 10 metros (Fig.1).

0 cálculo do tamanho mínimo da amostra foi determinado pela fórmula do Centro Panamericano de Zoonoses (1997), em que: $\mathrm{N}=\mathrm{p} .(100-\mathrm{p}) \mathrm{Z}^{2} /(\mathrm{d} . \mathrm{p} / 100)^{2}$, sendo $\mathrm{N}=$ número de amostras; $\mathrm{p}=$ prevalência esperada; $\mathrm{Z}=$ grau de confiança e $\mathrm{d}=$ margem de erro. Para os valores de prevalência esperada (p) para Babesia bovis e Babesia bigemina em búfalos, foi utilizado o estudo de Guedes Jr et al. (2008). 0 intervalo de confiança foi de $95 \%$ e a margem de erro foi de $5 \%$. Desta forma, selecionou-se 800 bubalinos por amostragem aleatória. Os animais eram da raça Murrah,

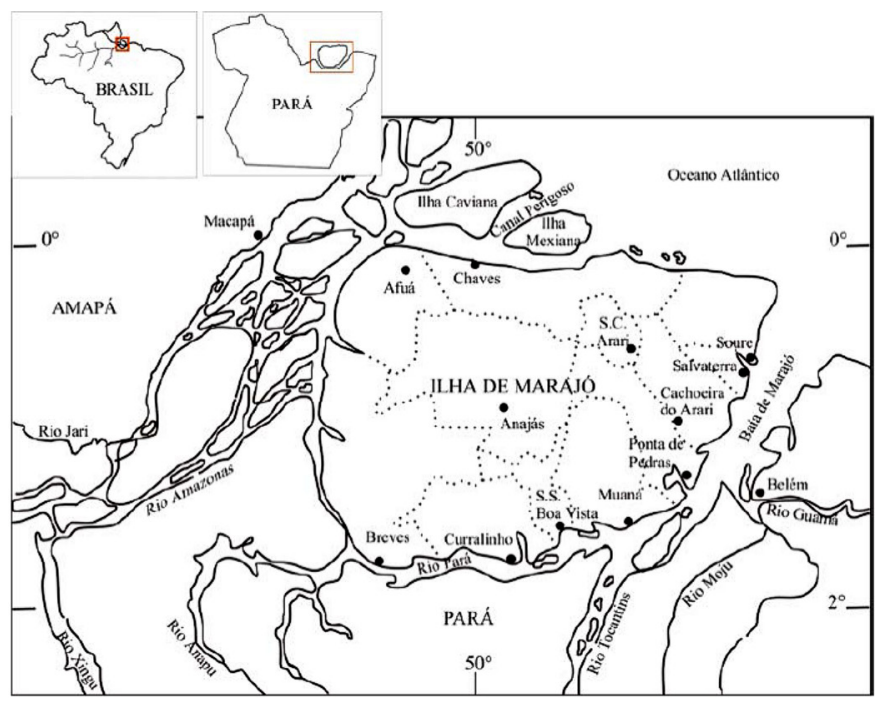

Fig.1. Ilha de Marajó com 12 municípios, limitada pela Baia de Marajó, rio Pará e Oceano Atlântico.

com idade entre um e três anos, do sexo feminino e mantidos em sistema de criação extensiva.

Os títulos de anticorpos anti-B. bovis e anti-B. bigemina foram determinados pelo Ensaio de Imunoadsorção Enzimático indireto (iELISA), segundo Machado et al. (1997). Como controles positivos, foram utilizados soros de bubalinos com alta parasitemia (qPCR) e título de anticorpos (ELISA e RIFI). Como controles negativos, utilizaram-se soros de bubalinos recém nascidos que não ingeriram colostro e negativos na PCR e ELISA/RIFI. A leitura foi realizada em leitor de ELISA, em um comprimento de onda de $405 \mathrm{~nm}$.

A atividade enzimática de cada soro no ELISA foi calculada mediante determinação do valor da amostra em relação ao referencial positivo (A/P). Os valores A/P foram agrupados em níveis ELISA (NE), que variaram de zero a nove. A amplitude máxima do NE zero foi determinada pela média dos valores em absorbância de soros de animais soronegativos acrescida de dois desvios padrões da média, conforme estabelecido por Machado et al. (1997). A partir deste limite, os intervalos entre os outros níveis no ELISA foram acrescidos de 35\% cada, segundo Wilson et al. (1984) para o sistema Newcastle. 0 ponto de corte do teste foi determinado usando a média da densidade óptica (D0) de soros de animais negativos para B. bovis e B. bigemina multiplicado por 2,5.

Foram selecionados aleatoriamente 25\% (200/800) das amostras para realização da PCR. A PCR e oELISA foram feitas de forma independentes. Para maior integridade e confiabilidade dos dados o ELISA foi realizado no Laboratório de Doenças Parasitárias da UFRRJ e a PCR no Laboratório de Biologia Molecular Animal da Embrapa Gado de Corte. Todas as amostras colhidas foram submetidas ao ELISA. Porém, apenas uma parte foi aleatoriamente selecionada para a PCR logo após a colheita. Essa seleção foi feita antes mesmo que as amostras tivessem sido submetidas ao ELISA. A PCR foi realizada segundo Buling et al. (2007). Para isso o DNA das amostras foi extraído, utilizando o QIAamp DNA Blood Mini Kit (Qiagen $®$ ), para determinar e quantificar os níveis parasitêmicos de B. bovis e B. bigemina.

As frequências de animais positivos no ELISA e na PCR para $B$. bovis e B. bigemina foram comparadas pelo teste de Qui-quadrado com $95 \%$ de confiabilidade. A concordância entre a frequência de animais positivos na PCR convencional e no ELISA foi avaliada utilizando o índice Kappa (Kramer \& Feinstein 1981). Os procedimentos operacionais foram feitos utilizando o software Rstudio, Foundation computação estatística, versão 2.12 .2 (2011). 


\section{RESULTADOS}

Os valores médios e desvios padrões da densidade óptica dos controles negativos e positivos para Babesia bovis foi $0.127 \pm 0.01$ e $1.026 \pm 0.04$ e para Babesia bigemina foi $0.121 \pm 0.01$ e $1.008 \pm 0.06$, respectivamente. A classificação dos soros em níveis de ELISA (NE) está representada no Quadro 1.

Entre as amostras avaliadas simultaneamente por ELISA e PCR, observou-se que a positividade foi de $20 \%$ no ELISA e 15\% na PCR e que apenas 5\% das amostras foram positivas no ELISA e na PCR. Esses resultados demonstram que apenas $33 \%$ das amostras positivas na PCR foram diagnosticadas como positivas no ELISA. Porém, quando somado as amostras positivas dos dois testes, observou-se que $35 \%$ das amostras foram positivas, demonstrando um acréscimo na sensibilidade, o que aumentou as chances de diagnóstico positivo (Quadro 2).

A soroprevalência para B. bovis foi de 24.87\% (199/800) e para B. bigemina $20.75 \%(166 / 800)$. Entre os animais soropositivos, $22.79 \%(49 / 215)$ possuíam anticorpos apenas anti-B. bovis e, 7.44\% (16/215) apenas para B. bigemina e $69.76 \%(150 / 215)$ possuíam anticorpos circulantes contra os dois agentes (Quadro 3). Pela PCR foi detectado a presença de B. bovis em 15\% (18/200) de B. bigemina em 16\% $(19 / 200)$ dos animais, sendo que destes, $58 \%(11 / 19)$ apresentavam-se co-infectados (Quadro 4). Os resultados apresentaram moderada correlação entre o ELISA e PCR $(\mathrm{kappa}=0.62)$.

Quadro 1. Valores de densidade óptica dos níveis de ELISA (NE) para Babesia bovis e Babesia bigemina e percentual de animais (\%) em cada intervalo

\begin{tabular}{ccccc}
\hline NE & A/P & B. bovis & A/P & B. bigemina \\
\hline 0 & $0-0.147$ & $20 \%$ & $0-0.129$ & $25 \%$ \\
1 & $0.148-0.200$ & $35 \%$ & $0.130-0.175$ & $21 \%$ \\
2 & $0.201-0.271$ & $15 \%$ & $0.176-0.238$ & $23 \%$ \\
3 & $0.272-0.367$ & $10 \%$ & $0.239-0.323$ & $13 \%$ \\
4 & $0.368-0.497$ & $10 \%$ & $0.324-0.437$ & $9 \%$ \\
5 & $0.498-0.672$ & $4 \%$ & $0.438-0.591$ & $3 \%$ \\
6 & $0.673-0.908$ & $2 \%$ & $0.592-0.799$ & $1 \%$ \\
7 & $0.909-1.227$ & $3 \%$ & $0.800-1.080$ & $2 \%$ \\
8 & $1.228-1.658$ & $2 \%$ & $1.081-1.459$ & $3 \%$ \\
9 & $>1.658$ & $0 \%$ & $>1.459$ & $0 \%$
\end{tabular}

Quadro 2. Detecção sorológica e molecular de Babesia sp. em búfalos, Ilha do Marajó, Pará

\begin{tabular}{lcc}
\hline \multicolumn{1}{c}{ Babesia sp. } & \multicolumn{2}{c}{ PCR } \\
\cline { 2 - 3 } ELISA & Positivo & Negativo \\
Positivo & 5 & 20 \\
Negativo & 10 & 65 \\
Quadro 3. Prevalência de búfalos soropositivos \\
para Babesia bovis e Babesia bigemina por \\
ensaio de imunoadsorção enzimático, Ilha do \\
\multicolumn{2}{c}{ Marajó, Pará } \\
\hline \multicolumn{2}{c}{ ELISA } & Babesia bigemina \\
\cline { 2 - 3 } & Positivo & Negativo \\
\hline Pabesia bovis & 150 & 49 \\
Negativo & 16 & 585
\end{tabular}

\begin{tabular}{|c|c|c|}
\hline \multicolumn{3}{|c|}{$\begin{array}{c}\text { Quadro 4. Prevalência de búfalos positivos } \\
\text { para Babesia bovis e Babesia bigemina por } \\
\text { reação em cadeia da polimerase, Ilha do } \\
\text { Marajó, Pará }\end{array}$} \\
\hline \multirow[t]{2}{*}{ PCR } & \multicolumn{2}{|c|}{ Babesia bigemina } \\
\hline & Positivo & Negativo \\
\hline \multicolumn{3}{|l|}{ Babesia bovis } \\
\hline Positivo & 11 & 7 \\
\hline Negativo & 8 & 174 \\
\hline
\end{tabular}

\section{DISCUSSÃO}

A prevalência sorológica e molecular de Babesia bovis e Babesia bigemina observadas neste estudo foi inferior aos resultados encontrados por Guedes et al. (2008) no Brasil e superiores aos encontrados por Terkawi et al. (2011) na Thailândia e por He et al. (2012) na China. A prevalência sorológica neste estudo foi 1.7 e 4.1 vezes maior do que Terkawi et al. (2011) observaram na Thailândia e 24 e 28 vezes maior do que He et al. (2012) observaram na China, para $B$. bovis e B. bigemina, respectivamente. Neste estudo, o número de amostras co-infestadas (18.75\%) foram superiores aos 3.9\% observados por He et al. (2012).

A baixa frequência de búfalos soropositivos para $B$. bovis e B. bigemina sugere uma baixa taxa de transmissão desses organismos por carrapatos na região estudada. Esses resultados classificam a área como endemicamente instável para estes hemoprotozoarios, segundo classificação de Mahoney \& Ross (1972) e Terkawi et al. (2011). Assim, os búfalos podem atuar como reservatórios da babesiose bovina, representando um risco para rebanhos onde búfalos e bovinos são mantidos juntos.

$\mathrm{Na}$ avaliação molecular, os resultados deste estudo são 1.3 e 4.4 vezes superiores aos observados por Terkawi et al. (2011) para B. bovis e B. bigemina, respectivamente. No Brasil poucos estudos moleculares foram realizados para agentes da babesiose em búfalos. Corrêa (2011), embora tenha observado alta soroprevalência para Babesia sp., encontrou apenas um animal positivo na PCR para B. bovis e nenhum para B. bigemina.

Os resultados dos testes moleculares e serológicos não apresentaram alta concordância (kappa $=0.62$ ). Estes resultados são similares aos observados por Corrêa (2011) e diferentes dos de Terkawi et al. (2011), que observaram alta concordância entre os testes. Porém, o número de animais positivos nestes dois estudos foi muito baixo, dificultando uma análise mais detalhada dos dados. Nossos resultados demonstram que a melhor alternativa em estudos sanitários e levantamentos epidemiológicos da babesiose bubalina seria a combinação entre as duas técnicas.

Na Argentina, Ferreri et al. (2008) observaram na província de Corrientes que, de 103 amostras de búfalos examinadas para B. bovis, apenas 35 (34\%) tiveram reação positiva, enquanto um significativo número de amostras positivas na PCR foram detectadas em amostras da província de Lavalle 22/36 (61\%). 0 hábito dos bubalinos manterem-se submersos na água pode é a explicação mais aceitável para a baixa prevalência de carrapatos e, consequentimente Babesia sp. em relação aos resultados observados para bovinos (Somparn et al. 2004, Terkawi et al. 2011). 
Na Índia, os búfalos, em condições naturais, são raramente acometidos pela forma clínica da babesiose e acredita-se que sejam refratários a essa infecção devido à resistência imunológica natural (Roychoudhury \& Gautam 1979). Porém, outros trabalhos relatam a babesiose como preocupante no rebanho bubalino da Índia. Muraleedharan et al. (1984) mencionaram que B. bigemina era comum tanto em búfalos quanto em bovinos.

Banerjee et al. (1988) observaram que os búfalos quando parasitados por B. bigemina não sofrem severamente, mas podem ser reservatórios em potencial para os bovinos, quando estes coabitam as mesmas pastagens. Assim, o elevado número de animais positivos na PCR e o baixo percentual de animais soropositivos no ELISA demonstram que estes animais podem ser vulneráveis e funcionar como um reservatório do agente no estado do Pará, o qual tem um dos maiores rebanhos bovinos do país e encontra-se em franca expansão.

\section{CONCLUSÕES}

Os resultados mostram uma baixa prevalência de anticorpos anti-Babesdia bovis e anti-Babesia bigemina em búfalos da Ilha do Marajó.

Porém, observou-se que os agentes da babesiose bovina circulam em búfalos, podendo os mesmos atuar como reservatórios.

Agradecimentos.- Ao Conselho Nacional de Desenvolvimento Científico e Tecnológico (CNPq), à Pró-Reitoria de Pesquisa e Pós-Graduação da Universidade Federal do Pará (PROPESP/UFPA) e à Fundação de Amparo e Desenvolvimento da Pesquisa (FADESP) pelo apoio financeiro.

\section{REFERÊNCIAS}

Araujo F.R., Madruga C.R., Leal C.R., Schenk M.A., Kessler R.H., Marques A.P. \& Lemaire D.C. 1998. Comparison between enzyme-linked immunosorbent assay, indirect fluorescent antibody and rapid conglutination test in detecting antibodies against Babesia bovis. Vet. Parasitol. 74:101108.

Buling A., Criado-Fornelio A., Asenzo G., Benitez D., Barba-Carretero J.C. \& Florin-Christensen M. 2007. A quantitative PCR assay for the detection and quantification of Babesia bovis and B. bigemina. Vet. Parasitol. 147:16-25.

Corrêa F.N. 2011. Estudo epidemiológico de Borrelia burgdorferi, Babesia bovis, Babesia bigemina e Anaplasma marginale em búfalos (Bubalus bubalis) do Estado do Rio de Janeiro. Tese de Doutorado, Universidade Federal Rural do Rio de Janeiro, Seropédica, RJ. 99p.

De la Fuente J., Naranjo V., Ruiz-Fons F., Höfle U., Mera I.G.F., Villanúa D., Almazán C., Torina A., Caracappa S., Kocan K.M. \& Gortázar C. 2005. Potential vertebrate reservoir hosts and invertebrate vectors of Anaplas- ma marginale and A. phagocytophilum in Central Spain. Vector Borne Zoonotic Dis. 5:390-401.

Fahrimal Y., Goff W.L. \& Jasmer D.P. 1992. Detection of Babesia bovis carrier cattle by using polymerase chain reaction amplification of parasite DNA. J. Clin. Microbiol. 30:1374-1379.

Ferreri L., Benitez D., Dominguez, M., Rodriguez A., Asenzo G., Mesplet M., Florin-Christensen M. \& Schnittger L. 2008. Water buffalos as carriers of Babesia bovis in Argentina: animal biodiversity and emerging diseases. Ann. N.Y. Acad. Sci. 1149:149-151.

Figueroa J.V., Chieves L.P., Johnson G.S. \& Buening G.M. 1993. Multiplex polymerase chain reaction based assay for the detection of Babesia bigemina, Babesia bovis and Anaplasma marginale DNA in bovine blood. Vet. Parasitol. 50:69-81.

Goo Y.K., Jia H., Aboge G.O., Terkawi M.A., Kuriki K., Nakamura C., Kumagai A., Zhou J., Lee E.G., Nishikawa Y., Igarashi I., Fujisaki K. \& Xuan X. 2008. Babesia gibsoni: serodiagnosis of infection in dogs by an enzymelinked immunosorbent assay with recombinant BgTRAP. Exp. Parasitol. 118:555-560.

Grisi L., Massard C.L., Borja G.E.M. \& Pereira J.B. 2002. Impacto econômico das principais ectoparasitoses em bovinos no Brasil. Hora Vet. 21:8-10.

Guedes-Junior D.S., Araújo F.R., Silva F.J.M., Rangel C.P., Barbosa-Neto J.D. \& Fonseca A.H. 2008. Frequency of antibodies to Babesia bigemina, B. bovis, Anaplasma marginale, Trypanosoma vivax and Borrelia burdgorferi in cattle from the northeastern region of the state of Pará, Brazil. Revta Bras. Parasitol. Vet. 17:105-109.

He L., Feng H.H., Zhang W.J., Zhang Q.L., Fang R., Wang L.X., Tu P., Zhou Y.Q., Zhao J.L. \& Oosthuizen M.C. 2012. Occurrence of Theileria and Babesia species in water buffalo (Bubalus babalis Linnaeus, 1758) in the Hubei province, South China. Vet. Parasitol. 186:490-496.

IBGE 2008. Instituto Brasileiro de Geografia e Estatística. Disponível em <www.ibge.gov.br> Acesso em 5 jun. 2011.

Kramer M.S. \& Feinstein A.R. 1981. Clinical biostatistics. LIV. The biostatistics of concordance. Clin. Pharmacol. Ther. 29:111-123.

Machado R.Z., Montassier H.J., Pinto A.A., Lemos E.G., Machado M.R.F., Valadão I.F.F., Barci L.G. \& Malheiros E.B. 1997. An enzyme-linked immunosorbent assay (ELISA) for the detection on antibodies against Babesia bovis in cattle. Vet. Parasitol. 71:17-26.

Muraleedharan K., Syed Ziauddin K., Gopalaswamy K., Muraleedhar T. \& Seshadri S.J. 1984. Some observations on clinical cases of Babesia bovis (Babes, 1888) Starcovici, 1893, in buffaloes (Bubalus bubalis). Indian Vet. J. 61:76-79.

Roychoudhury G.K. \& Gautam O.P. 1979. Experimental studies on the pathogenicity of Babesia bigemina in buffalo calves. Trop. Anim. Health Prod. 11:91-93.

Terkawi M.A., Huyen N.X., Shinuo C., Inpankaew T., Maklon K., Aboulaila M., Ueno A., Goo Y.K., Yokoyama N., Jittapalapong S., Xuan X. \& Igarashi I. 2011. Molecular and serological prevalence of Babesia bovis and Babesia bigemina in water buffaloes in the northeast region of Thailand. Vet. Parasitol. 178:201-207.

Wilson R.A., Perrota Jr C., Frey B. \& Eckroade R.J. 1984. An enzyme-linked immunosorbent assay that measures protective antibody levels to Newcastle disease virus in chickens. Avian Dis. 28:1079-1085. 